\title{
Dome-Shaped Macula and Foveal Neurosensory Retinal Detachment-A Case Series
}

\author{
Torres Soriano Mitzy1,2,3*, Dimattia Jesica1, Gordon Maximiliano1,2 \\ ${ }^{1}$ Hospital Provincial del Centenario, Rosario, Argentina \\ ${ }^{2}$ Centro de la Visión Gordon-Manavella, Rosario, Argentina \\ ${ }^{3}$ Clínica de Ojos “Dr. Carlos Ferroni”, Rosario, Argentina \\ Email: *mitzytorres@yahoo.com
}

How to cite this paper: Mitzy, T.S., Jesica, D. and Maximiliano, G. (2019) Dome-Shaped Macula and Foveal Neurosensory Retinal Detachment-A Case Series. Open Journal of Ophthalmology, 9, 151-160.

https://doi.org/10.4236/ojoph.2019.93016

Received: July 2, 2019

Accepted: August 25, 2019

Published: August 28, 2019

Copyright (c) 2019 by author(s) and Scientific Research Publishing Inc. This work is licensed under the Creative Commons Attribution International License (CC BY 4.0).

http://creativecommons.org/licenses/by/4.0/

cc) (i) Open Access

\begin{abstract}
Objective: To report a case series of dome-shaped macula (DSM) and serous retinal detachment (SRD). Methods: A retrospective and observational case series study was performed at two centers of ophthalmology in Rosario-Argentina from January 2016 to December 2017. Eight eyes of 5 patients diagnosed with dome-shaped macula with subfoveal hyporeflective zone seen in optical coherence tomography (OCT) were included. Best-corrected visual acuity (BCVA), OCT, fluorescein angiography (FA), differential diagnoses, clinical course and different treatments were reviewed. Results: Baseline visual acuity ranged from $20 / 25$ to $20 / 200$. OCT revealed that the retinal choroidal macular complex had a convex shape and exhibited foveal neurosensory retinal detachment in all cases. FA showed mild diffuse hyperfluorescence due to changes in the retinal pigment epithelium (RPE). No sign of leakage was observed. Different treatments were used, including intravitreal antiangiogenic drugs, oral spironolactone, melatonin and observation. Follow-up time was between 6 and 18 months. BCVA and OCT findings remained unchanged after different options of treatment. Conclusions: DSM is an unusual entity, which can be confused with other maculopathies that cause neurosensory retinal detachment and do not respond to different types of treatment. Hence, in our opinion, observation is a reasonable approach for this disorder.
\end{abstract}

\section{Keywords}

Dome-Shaped Macula, Serous Retinal Detachment, Subretinal Fluid

\section{Introduction}

Dome shaped macula (DSM) was first described by Gaucher et al. as a rare find- 
ing characterized by an inward convexity of the macula within the concavity of the posterior staphyloma occurring in highly myopic patients [1].

The estimated prevalence of DSM was reported as $9.3 \%-10.7 \%$ in highly myopic eyes [1] [2] and 18\% in patients with choroidal neovascularization (CNV) secondary to pathologic myopia [3].

Serous retinal detachment (SRD) without choroidal neovascularization is a well-known complication of DSM and it is rarely reported in the absence of DSM [4]. While its physiopathological mechanism is still unknown, different theories have been proposed and include a thickening of the choroid [1] or a subfoveal scleral thickening that affects the flow of choroidal fluid [5].

Achieving a diagnosis of SRD associated with DSM can be challenging because it should be differentiated from other conditions associated with subretinal fluid (SRF) in the macular area, such as myopic CNV, idiopathic central serous chorioretinopathy, neovascular age-related macular degeneration (ARMD), polypoidal choroidal vasculopathy and tilted disc syndrome.

Because its pathophysiology is still unclear, no treatment has been identified. Few reports describing the successful treatment of SRD associated with DSM have been published, and the results reported in different reports have been variable. Some articles describe spontaneous resolution [6], while others describe treatment with half-fluence photodynamic therapy [7], argon laser photocoagulation, spironolactone [8] [9] and intravitreal antiangiogenic therapy [10].

Recently, some retrospective studies found that DSM is a condition that seems to remain stable over time even when is associated to chronic SRD [11] [12] in contrast to previous reports [13].

The objective of this study is to present five cases of DSM with SRD, including their refractive characteristics, clinical courses and the lack of successful results following a variety of therapeutic attempts.

\section{Methods}

A retrospective review of 8 eyes in 5 patients was conducted at two centers of ophthalmology in Rosario-Argentina from January 2016 to December 2017. The patients had been referred to us for diagnosis of visual complains or imaging of suspected fundus anomalies diagnosed in routine examination.

We analysed the following: BCVA using standard Early Treatment Diabetic Retinopathy Study (ETDRS) charts, refractive error, unilateral or bilateral DSM associated or not associated with SRD, spectral domain OCT and fluorescein angiography (FA) images, clinical course and treatments performed.

Dome-shaped macula was defined as a convexity of the retina-choroidal macular complex seen on spectral domain OCT images. In all patients, we achieved a diagnosis of DSM configuration based on spectral domain OCT (SD-OCT) images with vertical and horizontal scan patterns according to the description of Gaucher. SRD was defined as the hyporeflective subfoveal zone. Subfoveal choroidal thickness (SFCT) was measured with EDI-OCT (Spectralis, 
Heidelberg Engineering, Heidelberg, Germany) and was defined as the distance from the outer edge of the hyperreflective line corresponding to the RPE to the inner surface of the sclera. Increased SFCT was defined as measurement $>350$ micras [14].

The patients received different treatments, including spironolactone, intravitreal anti-VEGF, melatonin and observation. Details of each case are reported in the case report section.

This report was conducted in accordance with the Helsinki Declaration, and informed consent was obtained from patients, consistent with our institutional guidelines.

\section{Results}

We included 8 eyes in 5 patients with DSM and SRD confirmed by OCT. There were four female patients and one male patient. Age was ranged between 29 to 68 years.

Refractive error was high myopia ( $>6 \mathrm{D})$ in 4 eyes, low myopia $(<6 \mathrm{D})$ in 2 eyes and hypermetropia in 2 eyes. All patients had a bilateral configuration of DSM, but 3 of them presented bilateral SRD associated and two were unilateral.

Baseline visual acuity ranged from 20/25 to 20/200. OCT revealed a convex shape of the retinal choroidal macular complex, foveal neurosensory retinal detachment and increased SFCT in all cases. FA revealed mild diffuse hyperfluorescence due to changes in the retinal pigment epithelium (RPE). No sign of leakage was observed. The treatments performed included intravitreal antiangiogenic drugs, oral spironolactone, melatonin and observation.

BCVA and OCT findings remained unchanged after different options of treatment over time. The follow-up was between 6 to 18 months.

Table 1 showed data of five patients included in the study (Table 1).

\section{Case Reports}

1) Case 1: A 48-year-old female patient who had been insulin-dependent diabetic for 17 years came to the clinic due to loss of visual acuity with 8 months of evolution. BCVA was 20/200 in both eyes (OU), and refraction was $-1.75:-1.50 \times$ $15^{\circ}$ in the right eye (OD) and $-1.50:-3.00 \times 180^{\circ}$ in the left eye (OS). Fundoscopy showed atrophic changes in the RPE at the macular area in the OU. FA confirmed early hyperfluorescence in the macula caused by window defect due to atrophic changes, and no leakage point was observed. OCT showed dome-shaped maculopathy with subfoveal hyporeflective zone (Figure 1). She was treated with spironolactone $(50 \mathrm{mg}$ ) for 3 months, and no positive response was observed in BCVA and OCT results during 12 follow-up.

2) Case 2: A 45-year-old female patient presented with a history of corneal refractive surgery (LASIK) in OU due to high myopia. BCVA was 20/70 (-3.50: $-1 \times$ $\left.150^{\circ}\right)$ in OD, and $20 / 50\left(-1.50:-0.75 \times 55^{\circ}\right)$ in the OS. Ophthalmoscopic exam revealed a tilted disc, myopic fundus, posterior staphyloma and changes in the 
Table 1. Summary of the clinical findings.

\begin{tabular}{|c|c|c|c|c|c|c|c|c|c|}
\hline Case & $\begin{array}{l}\text { Sex } \\
\text { Age }\end{array}$ & History & Eye & $\begin{array}{l}\text { Refractive } \\
\text { Error }\end{array}$ & BCVA & OCT & FA & $\begin{array}{c}\text { Initial } \\
\text { Management }\end{array}$ & Response \\
\hline 1 & $\begin{array}{c}\text { P } \\
48 \text { y.o. }\end{array}$ & $\begin{array}{l}\text { Insulin-dependent } \\
\text { Diabetes Mellitus }\end{array}$ & OU & Low myopia & $\begin{array}{l}20 / 200 \\
(\mathrm{OU})\end{array}$ & $\begin{array}{l}\text { DSM with } \\
\text { SRD (OU) }\end{array}$ & $\begin{array}{l}\text { Early diffuse } \\
\text { hyperfluorescence, } \\
\text { atrophic changes. No } \\
\text { leakage points. }\end{array}$ & $\begin{array}{l}\text { Spironolactone } \\
50 \mathrm{mg} / \text { day for } \\
3 \text { months }\end{array}$ & Stable \\
\hline 2 & $\begin{array}{c}q \\
45 \text { y.o. }\end{array}$ & $\begin{array}{l}\text { Corneal refractive } \\
\text { surgery }(\mathrm{OU})\end{array}$ & OU & $\begin{array}{l}\text { High } \\
\text { myopia }\end{array}$ & $\begin{array}{l}\text { OD: } 20 / 70 \\
\text { OS: } 20 / 50\end{array}$ & $\begin{array}{l}\text { DSM with } \\
\text { SRD (OU) }\end{array}$ & $\begin{array}{l}\text { Early diffuse } \\
\text { hyperfluorescence, } \\
\text { atrophic changes. } \\
\text { No leakage points. }\end{array}$ & $\begin{array}{l}\text { Melatonin } \\
9 \mathrm{mg} / \text { day for } \\
1 \text { month }\end{array}$ & Stable \\
\hline 3 & $\begin{array}{c}\delta^{\lambda} \\
29 \text { y.o. }\end{array}$ & Pseudophakia (OU) & OD & $\begin{array}{l}\text { High } \\
\text { myopia }\end{array}$ & $\begin{array}{l}\text { OD: } 20 / 30 \\
\text { OS: } 20 / 40\end{array}$ & $\begin{array}{l}\text { DSM with } \\
\text { SRD (OD) } \\
\text { DSM without } \\
\text { SRD (OS) }\end{array}$ & $\begin{array}{l}\text { Early diffuse } \\
\text { hyperfluorescence, } \\
\text { atrophic changes. } \\
\text { No leakage points. }\end{array}$ & Observation & Stable \\
\hline 4 & $\begin{array}{c}q \\
68 \text { y.o. }\end{array}$ & $\begin{array}{l}\text { Corneal refractive } \\
\text { surgery and } \\
\text { pseudophakia (OU) }\end{array}$ & OS & $\begin{array}{l}\text { High } \\
\text { myopia }\end{array}$ & $\begin{array}{l}\text { OD: } 20 / 40 \\
\text { OS: } 20 / 30\end{array}$ & $\begin{array}{l}\text { DSM without } \\
\text { SRD (OD) } \\
\text { DSM with } \\
\text { SRD (OS) }\end{array}$ & $\begin{array}{l}\text { Early diffuse } \\
\text { hyperfluorescence, } \\
\text { atrophic changes. } \\
\text { No leakage points. }\end{array}$ & $\begin{array}{c}\text { Intravitreal } \\
\text { anti-VEGF } \times 6 \\
(\mathrm{OS})\end{array}$ & Stable \\
\hline 5 & $\begin{array}{c}\stackrel{p}{+} \\
61 \text { y.o. }\end{array}$ & $\begin{array}{l}\text { Treatment with } \\
\text { topiramate. } \\
\text { Retinochoroidal } \\
\text { coloboma (OS) }\end{array}$ & $\mathrm{OU}$ & Hyper-metropia & $\begin{array}{l}\text { OD: } 20 / 25 \\
\text { OS: } 20 / 30\end{array}$ & $\begin{array}{l}\text { DSM with } \\
\text { SRD (OU) }\end{array}$ & $\begin{array}{l}\text { Early diffuse } \\
\text { hyperfluorescence, } \\
\text { atrophic changes. } \\
\text { No leakage points. }\end{array}$ & Observation & Stable \\
\hline
\end{tabular}

RPE in the macular area. OCT confirmed DSM with subfoveal hyporeflective zone, and FA showed early diffuse hyperfluorescence without leakage points (Figure 2). Observation was the initial management. After a follow up period of 12 months, BCVA decreased in both eyes, for this reason treatment with melatonin $(9 \mathrm{mg} /$ day) was indicated for one month. At one, three and six months of follow-up no changes were observed.

3) Case 3: A 29-year-old male patient presented with high myopia with pseudophakia in the OU, BCVA was $20 / 30\left(-0.75 \times 111^{\circ}\right)$ in the OD and 20/40 $(-1.00$ $\left.\times 167^{\circ}\right)$ in the OS. A fundus exam of OD showed myopic fundus, pigmented temporal lesion at the macula and pigmentary changes. In the OS, myopic fundus and pigmentary changes were observed. OCT revealed DSM in both eyes with a subfoveal hyporeflective zone in the right eye. Observation was the approach in this case. During the follow-up (18 months), BCVA and OCT did not reveal any changes.

4) Case 4: A 68-year-old female patient presented with high myopia and a history of corneal refractive surgery and pseudophakia in OU. She relates that another healthcare provider administered 6 doses of an intravitreal antiangiogenic drug in OS due to suspected wet ARMD. According to the eye examination, BCVA was 20/40 $\left(-0.25:-1.5 \times 175^{\circ}\right)$ in the OD and 20/30 $(-1:-0.75 \times$ $\left.160^{\circ}\right)$ in the OS. Fundoscopy showed myopic fundus, posterior staphyloma, a tilted disc and pigmentary changes at the macula. OCT revealed a deformity in DSM in both eyes and subfoveal hyporeflective zone in the OS. No response to 

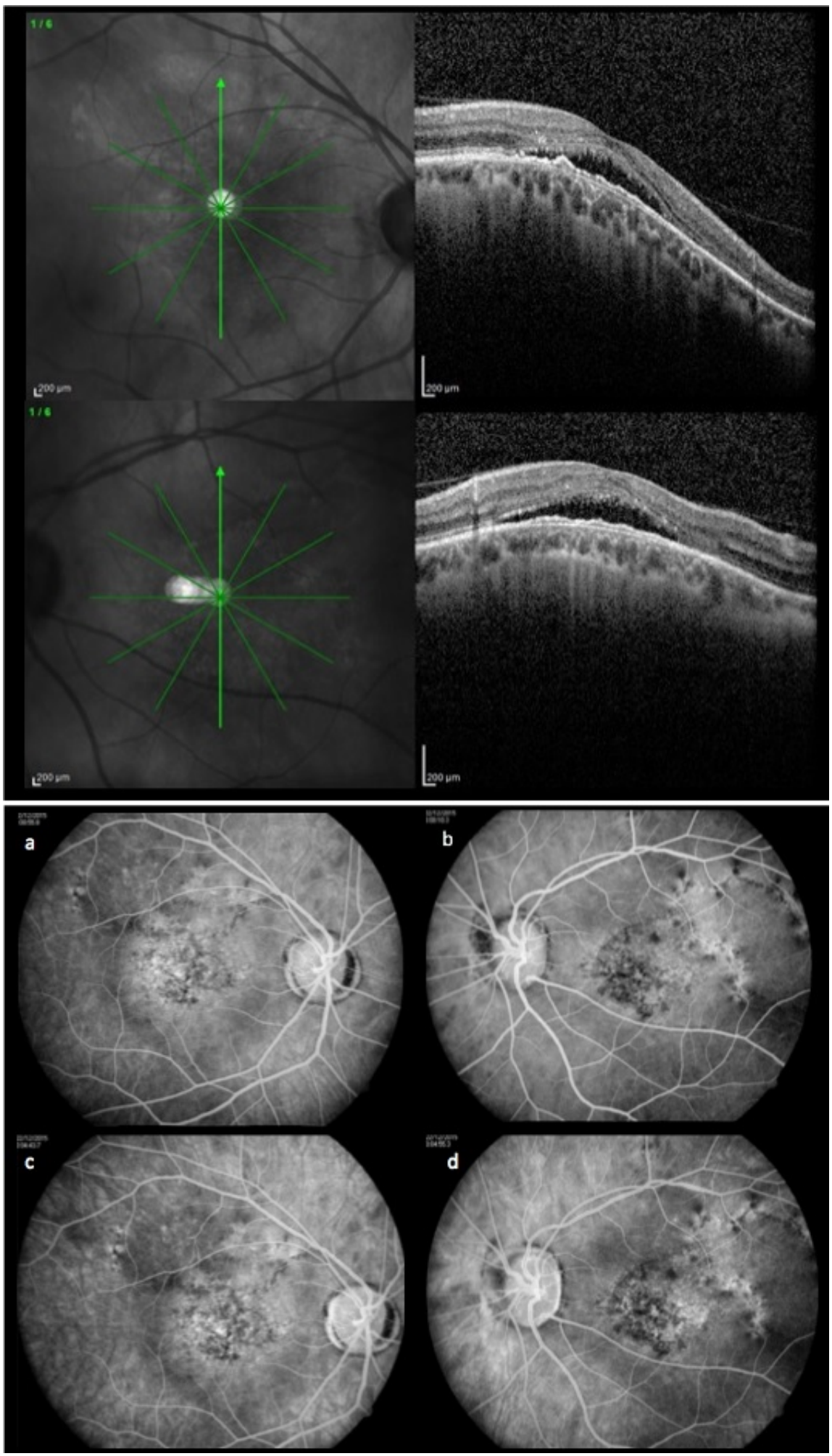

Figure 1. Top image: Bilateral DSM configuration in a 48-year-old female patient with mild myopia. Serous retinal detachment is clearly visible on an SD OCT vertical scan (top right), which shows a very small detachment of the retinal pigment epithelium (RPE). Partial posterior vitreous detachment and choroidal thickening were also observed. Bottom image: FA showing hyperfluorescence due to RPE atrophic changes. No leaking point was observed. 

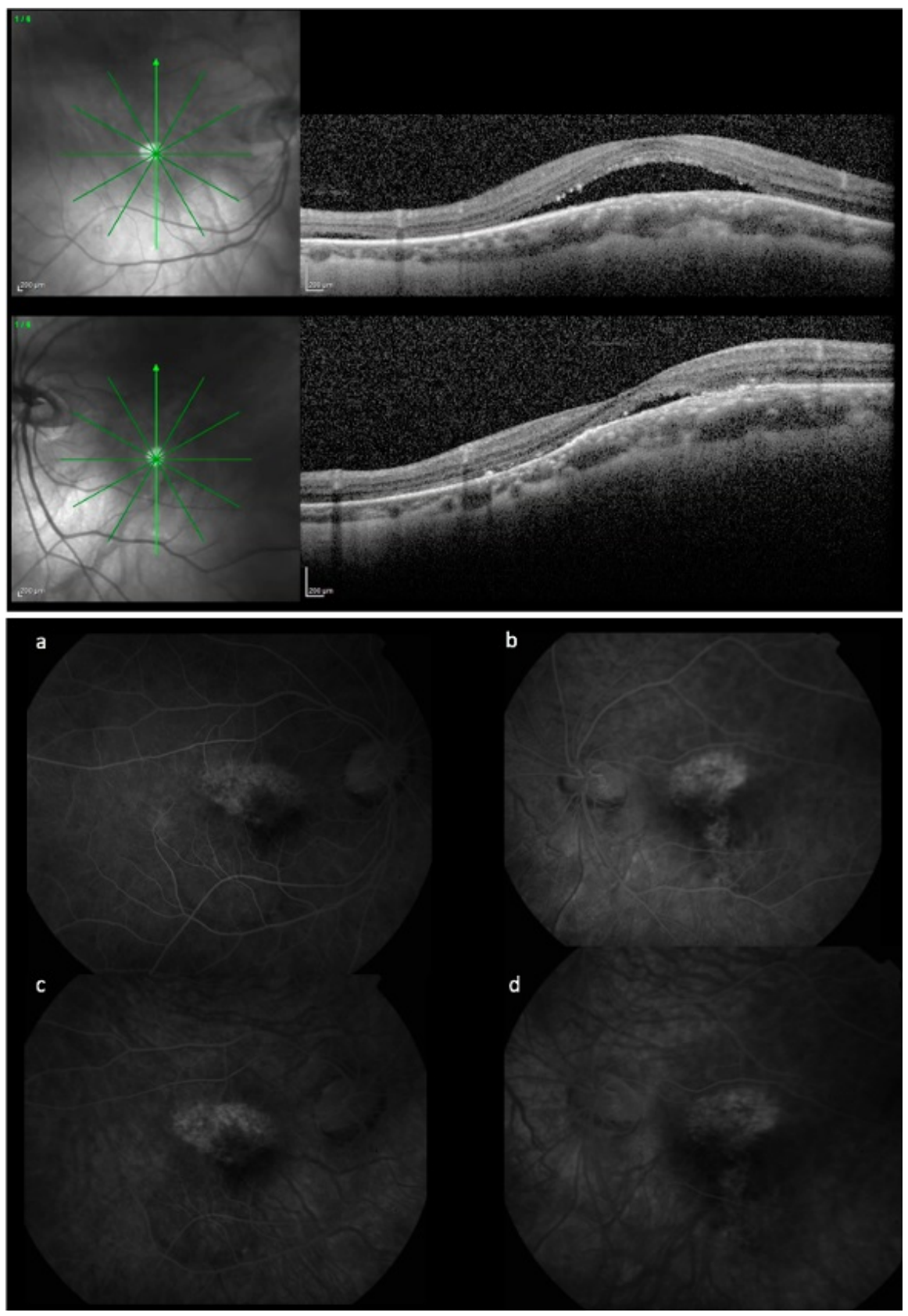

Figure 2. Bilateral DSM and SRD were confirmed by vertical scan SD-OCT in a 45-year-old female patient with high myopia (Top image). Choroidal thickening was observed. Bottom image: FA revealed macular hyperfluorescence in early ((a) and (b)) and late $((\mathrm{c})$ and $(\mathrm{d}))$ phases, but not active leakage.

anti-VEGF treatment was observed. This patient was followed up for 18 months and remained stable.

5) Case 5: A 61-year-old patient being treated with topiramate came to the clinic due to bilateral maculopathy. BCVA was $20 / 25$ in OD $\left(+2:-2.5 \times 85^{\circ}\right)$ and 20/30 in the OS $\left(+1.25:-2.5 \times 70^{\circ}\right)$. Fundoscopy showed posterior staphyloma and pigmentary changes at the macular area in the OU. An inferior parapapillary retinochoroidal coloboma was observed in the OS. OCT confirmed DSM 
with a subfoveal hyporeflective zone in the OU, and early hyperfluorescence without leakage points was observed on FA (Figure 3). She remained under observation and there were no changes in BCVA or OCT findings during 18 months of follow-up.

\section{Discussion}

DSM was initially described in myopic patients. In 2015, Liang reported the

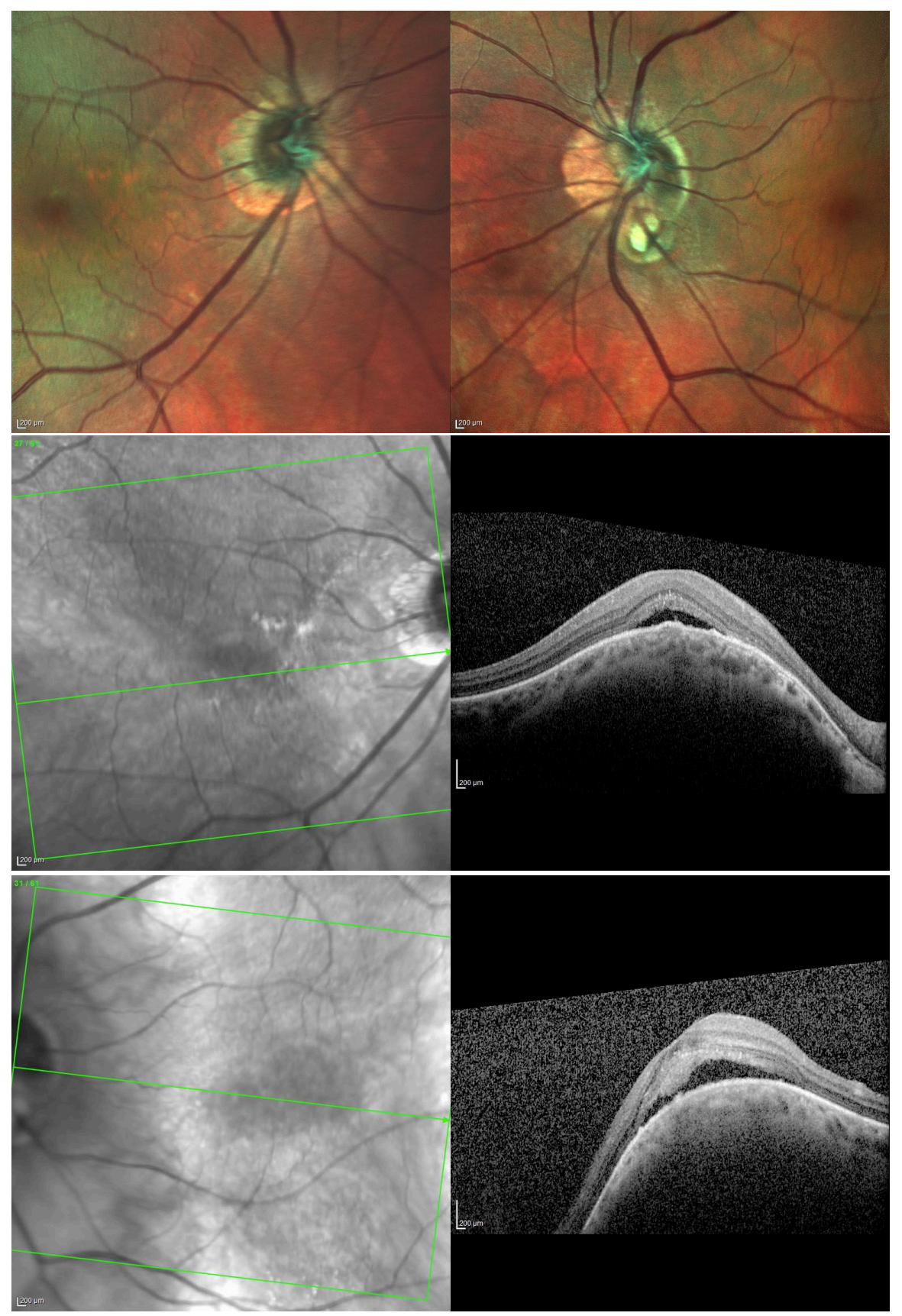

Figure 3. Bilateral DSM and SRD confirmed by SD-OCT in a 61-year-old female patient with hypermetropia but myopic fundus appearance. A small RPE detachment was observed in addition to hyperreflective subretinal fluid in OS (bottom left image). 
largest series of cases, in which 225 eyes with DSM were identified out of 1118 eyes with high myopia (20\%). [15] However, the last analysis of this data has revealed that DSM can occur in patients with moderate myopia, emmetropia and even hypermetropia. [11] This is consistent with our case series, in which one of the patients with DSM had low myopia and one had hypermetropia.

The most frequent complication of DSM is the presence of SRD. Its prevalence ranges from $28.5 \%$ to $66.6 \%$. However, the presence of subretinal fluid (SRF) was not associated with vision loss in comparison to patients without SRD [11] [12].

The cause of SRD is not known. Various hypotheses have been suggested. Imamura et al. proposed that SRD may be the result of an obstruction in the choroidal blood flow due to a thickening of the sclera, similar to the mechanism underlying uveal effusion in nanophthalmic eyes [5]. Others authors have observed submacular choroidal thickening, which suggests that the mechanism is similar to that of central serous chorioretinopathy (CSC) [4] [16].

Viola et al. proposed that the choroidal changes and thickening observed in DSM are due to a combination of mechanical and vascular damages to the choroid resulting from the excessive scleral thickening within the staphyloma. As a consequence, RPE damage, small RPE detachments and SRD in the upper part of the inner bulge caused by a slow choroidal leakage. However, while choroidal thickening in DSM is usually permanent, vascular abnormalities are temporary and can lead to SRD changes [4].

There is no consensus regarding which treatment is appropriate for SRD. Descriptions in the literature regarding the use of mineralocorticoids, laser, intravitreal antiangiogenic drugs and photodynamic therapy are limited, and their results have varied [4] [8] [11] [16].

A retrospective study carried out in France between 2005 and 2014 included 29 eyes with DSM, and of these, 47\% (7 eyes) of the patients with SRD resolved spontaneously, while 6 of them showed no improvement in visual acuity due to the presence of macular atrophy. Additionally, treatments with bevacizumab (2 eyes), triamcinolone ( 1 eye), photodynamic therapy ( 2 eyes), focal laser (1 eye) and eplerenone $50 \mathrm{mg} /$ day (6 eyes) were indicated. None of the cases of SRD resolved or relapsed during treatment or immediately afterwards [16].

Lorenzo et al. evaluated 56 eyes with DSM in their retrospective cases series and found that $52 \%$ of the cases had SRD. No differences were observed in BCVA or the resolution of SRF between those patients who received treatment with antiangiogenic drugs and photodynamic therapy and those who did not [11].

The relationship between SRD and macular atrophy is also variable. While some studies that demonstrated that macular atrophy increases progressively and that it is related to the height of the macular bulge, [8] [16] others did not find any differences between cases with and without SRD based on the size of atrophy [4]. 
DSM is a rare entity, and its pathophysiology and treatment approach are not clear. In this study, all patients presented an increase in choroidal thickness measured by SD-OCT, this can be the result of a choroidal fluid disturbance produced by the thickened scleral in the dome-shaped area.

We agree that the pathophysiological mechanism in DSM with SRD is similar to that observed in CSC. However, in this review, no points of leakage were observed in any case. In our opinion, this disorder may manifest as active and inactive phases over time.

Differential diagnosis includes other maculopathies that present with neurosensory retinal detachment. The main differential diagnoses are central serous chorioretinopathy (CSC), myopic CNV and choroidal hemangioma [17] [18]. Another disorder to consider in high myopia associated with SRD is tilted disc.

This study has various limitations. It had a small sample size, a retrospective design, and a short follow-up period, and no scleral measurements were obtained.

\section{Conclusion}

In this case series, consistent with the reviewed literature, DSM patients present a stable evolution and do not respond to different types of treatment. In our opinion, this makes observation a good alternative.

\section{Conflicts of Interest}

The authors declare no conflicts of interest regarding the publication of this paper.

\section{References}

[1] Gaucher, D., Erginay, A., Lecleire-Collet, A., et al. (2008) Dome-Shaped Macula in Eyes with Myopic Posterior Staphyloma. American Journal of Ophthalmology, 145, 909-914. https://doi.org/10.1016/j.ajo.2008.01.012

[2] Ohsugi, H., Ikuno, Y., Oshima, K., Yamauchi, T. and Tabuchi, H. (2014) Morphologic Characteristics of Macular Complications of a Dome-Shaped Macula Determined by Swept-Source Optical Coherence Tomography. American Journal of Ophthalmology, 158, 162-170. https://doi.org/10.1016/j.ajo.2014.02.054

[3] Ceklic, L., Wolf-Schnurrbusch, U., Gekkieva, M. and Wolf, S. (2014) Visual Acuity Outcome in Radiance Study Patients with Dome-Shaped Macular Features. Ophthalmology, 121, 2288-2289. https://doi.org/10.1016/j.ophtha.2014.06.012

[4] Viola, F., Dell'Arti, L., Benatti, E., et al. (2015) Choroidal Findings in Dome-Shaped Macula in Highly Myopic Eyes: A Longitudinal Study. American Journal of Ophthalmology, 159, 44-52. https://doi.org/10.1016/j.ajo.2014.09.026

[5] Imamura, Y., Iida, T., Maruko, I., et al. (2011) Enhanced Depth Imaging Optical Coherence Tomography of the Sclera in Dome-Shaped Macula. American Journal of Ophthalmology, 151, 297-302. https://doi.org/10.1016/j.ajo.2010.08.014

[6] Tamura, N., Sakai, T. and Tsuneoka, H. (2014) Spontaneous Resolution of Foveal Detachment in Dome-Shaped Macula Observed by Spectral Domain Optical Coherence Tomography. Clinical Ophthalmology, 8, 83-86. 
https://doi.org/10.2147/OPTH.S54903

[7] Chinskey, N.D. and Johnson, M.W. (2013) Treatment of Subretinal Fluid Associated with Dome-Shaped Macula. Ophthalmic Surgery, Lasers and Imaging Retina, 44, 593-595. https://doi.org/10.3928/23258160-20131010-01

[8] Dirani, A., Matet, A. and Behar-Cohen, F. (2014) Resolution of Foveal Detachment in Dome-Shaped Macula after Treatment by Spironolactone: A Report of Two Cases and Mini-Review of the Literature. Clinical Ophthalmology, 8, 999-1002. https://doi.org/10.2147/OPTH.S62267

[9] Fernández-Vega Sanz, Á., Rangel, C.M., Villota Deleu, E., Fernández-Vega Sanz, B. and Sánchez-Ávila, R.M. (2016) Serous Retinal Detachment Associated with Dome-Shaped Macula and Staphyloma Edge in Myopic Patients before and after Treatment with Spironolactone. Journal of Ophthalmology, 2016, Article ID: 8491320. https://doi.org/10.1155/2016/8491320

[10] Milani, P., Pece, A., Pierro, L., Seidenari, P., Radice, P. and Scialdone, A. (2010) Bevacizumab for Macular Serous Neuroretinal Detachment in Tilted Disk Syndrome. Journal of Ophthalmology, 2010, Article ID: 970580. https://doi.org/10.1155/2010/970580

[11] Lorenzo, D., Arias, L., Choudhry, N., et al. (2017) Dome-Shaped Macula in Myopic Eyes. Twelve-Month Follow Up. Retina, 37, 680-686. https://doi.org/10.1097/IAE.0000000000001222

[12] García-Ben, A., Garcia-Basterra, I., González-Gómez, A., et al. (2018) Comparison of Long-Term Clinical Evolution in Highly Myopic Eyes with Vertical Oval-Shaped Dome with or without Untreated Serous Retinal Detachment. British Journal of Ophthalmology, 103, 385-389. https://doi.org/10.1136/bjophthalmol-2018-311895

[13] Caillaux, V., Gaucher, D., Gualino, V., et al. (2013) Morphologic Characterization of Dome-Shaped Macula in Myopic Eyes with Serous Macular Detachment. American Journal of Ophthalmology, 156, 958-967. https://doi.org/10.1016/j.ajo.2013.06.032

[14] Kong, M., Choi, D.Y., Han, G., et al. (2018) Measurable Range of Subfoveal Choroidal Thickness with Conventional Spectral Domain Optical Coherence Tomography. Translational Vision Science and Technology, 7, 16. https://doi.org/10.1167/tvst.7.5.16

[15] Liang, I.C. (2017) Horizontal Ridge as a Posterior Pole Finding in a Highly Myopic Eye with Dome-Shaped Macula. Retina, 37, 1261-1262. https://doi.org/10.1097/IAE.0000000000001308

[16] Soudier, G., Gaudric, A., Gualino, V., et al. (2016) Long-Term Evolution of Dome-Shaped Macula. Increased Macular Bulge Associated with Extended Macular Atrophy. Retina, 36, 944-952. https://doi.org/10.1097/IAE.0000000000000806

[17] Shields, C.L., et al. (2015) Dome-Shaped Macula Simulating Choroidal Hemangioma in a Myopic Patient. Oman Journal of Ophthalmology, 8, 188-190. https://doi.org/10.4103/0974-620X.169899

[18] Ellabban, A.A., Tsujikawa, A., Matsumoto, A., et al. (2013) Three-Dimensional Tomographic Features of Dome-Shaped Macular by Swept-Source Optical Coherence Tomography. American Journal of Ophthalmology, 155, 320-328.

https://doi.org/10.1016/j.ajo.2012.08.007 